\title{
Stereoselective Enzymatic Synthesis of Heteroatom-Substituted Cyclopropanes
}

\author{
Oliver F. Brandenberg, ${ }^{\dagger}$ Christopher K. Prier, ${ }^{\dagger, \S \odot ~ K a i ~ C h e n, ~}{ }^{\dagger}$ A Anders M. Knight, ${ }^{\ddagger}{ }^{\dagger}$ Zachary Wu, ${ }^{\dagger}$ \\ and Frances H. Arnold* ${ }^{*} \dagger$
}
${ }^{\dagger}$ Division of Chemistry and Chemical Engineering, California Institute of Technology, 1200 East California Boulevard, Pasadena, California 91125, United States

${ }^{\ddagger}$ Division of Biology and Bioengineering, California Institute of Technology, 1200 East California Boulevard, Pasadena, California 91125, United States

\section{Supporting Information}

ABSTRACT: The repurposing of hemoproteins for non-natural carbene transfer activities has generated enzymes for functions previously accessible only to chemical catalysts. With activities constrained to specific substrate classes, however, the synthetic utility of these new biocatalysts has been limited. To expand the capabilities of non-natural carbene transfer biocatalysis, we engineered variants of Cytochrome $\mathrm{P} 45 \mathrm{O}_{\mathrm{BM} 3}$ that catalyze the cyclopropanation of heteroatom-bearing alkenes, providing valuable nitrogen-, oxygen-, and sulfur-substituted cyclopropanes. Four or five active-site mutations converted a single parent enzyme into selective catalysts for the synthesis of both cis and trans heteroatomsubstituted cyclopropanes, with high diastereoselectivities and enantioselectivities and up to 40000 total turnovers. This work highlights the ease of tuning hemoproteins by directed evolution for efficient cyclopropanation of new substrate classes and expands the catalytic functions of iron heme proteins.

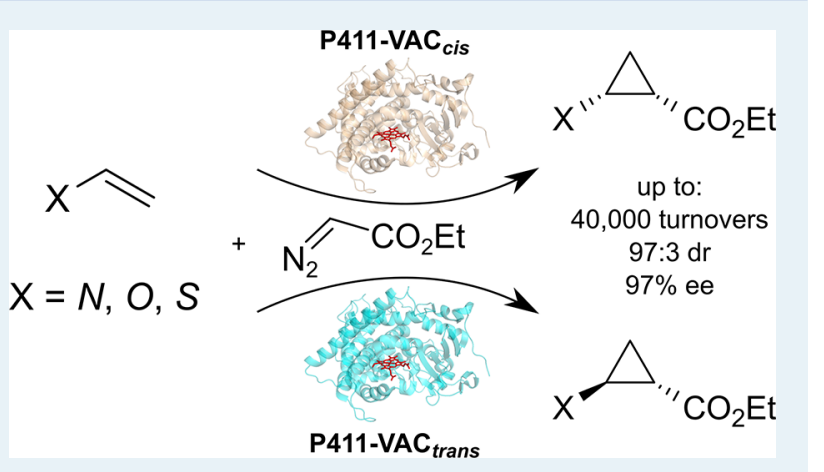

KEYWORDS: biocatalysis, Cytochrome P450, cyclopropanes, carbene transfer

$\mathrm{T}$ he cyclopropane ring is an important building block in organic synthesis and a structural motif in diverse bioactive compounds. ${ }^{1,2}$ Especially notable are heteroatom (nitrogen, oxygen, or sulfur)-substituted cyclopropanes, which appear in many natural products ${ }^{3}$ and biosynthetic intermediates (Scheme 1A). ${ }^{4}$ In pharmaceuticals, introduction of cyclopropylamines can substantially improve physicochemical and pharmacokinetic properties, ${ }^{5}$ and the cyclopropylamine functionality appears in the class of hepatitis $C$ virus protease inhibitors represented by simeprevir ${ }^{6}$ and grazoprevir. ${ }^{7}$ Novel biomaterials have also been constructed using $\beta$-aminocyclopropane carboxylic acids ( $\beta$-ACCs) and related compounds as rigid building blocks in synthetic peptides. ${ }^{8,9}$ Heteroatom-bearing cyclopropanes are additionally useful synthetic intermediates that engage in a variety of ring-opening transformations. ${ }^{10-13}$

Enantiomerically enriched cyclopropylamines are most commonly synthesized via Curtius or Hofmann rearrangements from the corresponding enantioenriched cyclopropylcarboxylic acids or amides. ${ }^{14,15}$ Chiral cyclopropylamines and cyclopropanols have also been synthesized via asymmetric phasetransfer catalysis ${ }^{16,17}$ and enzymatic resolution. ${ }^{18,19}$ Alternatively, forming the cyclopropane ring with control over stereochemistry by catalytic, enantioselective cyclopropanation of heteroatom-substituted alkenes represents a powerful approach to this class of compounds (Scheme 1B). Such reactions have been performed via carbene transfer with chiral ruthenium, ${ }^{20-24}$ rhodium, ${ }^{25-27}$ and copper $^{11,27}$ catalysts. Aminocyclopropanes have also been accessed via alkene cyclopropanation with nitro-substituted carbenoids, followed by reduction of the nitro group. ${ }^{28,29}$ However, many of the existing methods exhibit low catalyst turnover, proceed with only moderate levels of stereocontrol, are limited to specific substrate types, or require precious metals (e.g., $\mathrm{Ru}, \mathrm{Rh}$ ). Furthermore, these methods generally provide only the transcyclopropane products with high diastereoselectivity and enantioselectivity.

We and others have demonstrated that hemoproteins can be engineered to perform cyclopropanation reactions of olefins via carbene transfer. ${ }^{30-35}$ The synthetic utility of these "carbene transferases", engineered by directed evolution of cytochromes P450, myoglobins, and other proteins, has been demonstrated through preparative-scale syntheses of cyclopropane-containing pharmaceutical precursors. ${ }^{36-38}$ To date, however, almost all cyclopropanation reactions catalyzed by hemoproteins have required arene-substituted (styrenyl) olefins. In a first step toward broadening the substrate scope of enzyme-catalyzed

Received: December 23, 2017

Revised: February 7, 2018

Published: February 24, 2018 
Scheme 1. (A) Examples of Cyclopropylamines and Cyclopropanols in Natural Products, Pharmaceuticals, and Biomaterials; (B) Proposed Enzymatic Synthesis of Chiral Heteroatom-Substituted Cyclopropanes ${ }^{a}$

A<smiles>CCC1C=C(C(=O)NC2(C)CC2)C2(CCCC2=O)CC(=O)C2CCCC12</smiles><smiles>C=CC[C@H](NC(=O)[C@@H]1C[C@@H](Oc2nc3cc(OC)ccc3nc2CCCCCCC2CC2)CN1C(=O)[C@H](NC(=O)OC)C(C)(C)C)C(=O)NS(=O)(=O)C1CC1</smiles>

B

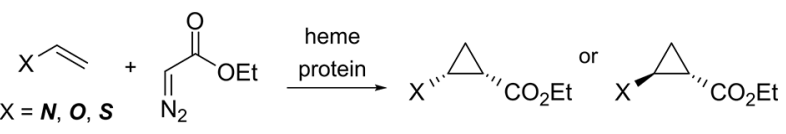

${ }^{a}$ Enzymatic carbene transfer to heteroatom-substituted alkenes generates heteroatom-substituted cyclopropanes in a single step with control over stereoselectivity.

cyclopropanation, we demonstrated recently that natural hemoprotein diversity can be leveraged to identify and engineer Cytochrome P450 and globin variants for the stereoselective cyclopropanation of unactivated, aliphatic alkenes, ${ }^{39}$ an activity previously achieved only by hemoproteins containing an artificial iridium co-factor. ${ }^{40-42}$ Gober et al. also recently reported engineered Cytochrome $\mathrm{P} 450$ variants for the cyclopropanation of dehydroalanine residues in thiopeptides, ${ }^{43}$ thereby enabling a non-natural modification of a complex natural product. We reasoned that diverse heteroatomsubstituted alkenes should be suitable coupling partners for electrophilic metal carbenoids derived from the reaction of diazo esters with genetically encoded heme proteins. This reaction would extend the scope of biocatalytic cyclopropanation to encompass a new class of synthetically important cyclopropanes (Scheme 1B). Here, we describe the directed evolution of Cytochrome P450 variants that cyclopropanate heteroatom-bearing alkenes to yield chiral $\mathrm{N}$-, O-, and S-cyclopropanes. The resulting enzymes outperform existing small-molecule catalysts, especially for challenging cisselective cyclopropanation reactions.

To gauge the potential of enzymatic heteroatom-substituted cyclopropane synthesis, we first tested a set of hemoproteins for cyclopropanation of $N$-vinylphthalimide (1) with ethyl diazoacetate (EDA, 2) as the carbene precursor (Figure 1), a reaction performed by free heme with a total turnover number (TTN) of 3 and 28:72 diastereomeric ratio (dr) (cis:trans) (see Table S2 in the Supporting Information). Enzymatic reactions were carried out with whole Escherichia coli (E. coli) cells expressing the hemoprotein variants and were analyzed for reaction yield and stereoselectivity (see Table S2). Variants of Cytochrome $\mathrm{P} 450_{\mathrm{BM} 3}$ from Bacillus megaterium were found to be active catalysts for synthesis of cyclopropane adduct 3, including several "P411" variants that feature a cysteine-toserine mutation at the residue ligating the iron center. ${ }^{31} \mathrm{E}$. coli expressing variant $\mathrm{P} 411_{\mathrm{BM} 3}$-CIS ${ }^{31}$ demonstrated promising diastereoselectivity (88:12 cis:trans), and this protein was selected for further engineering by directed evolution to enhance its catalytic activity.

To increase the activity of $\mathrm{P} 411_{\mathrm{BM}_{3}}$-CIS we performed parallel site-saturation mutagenesis at active site residues V87,
A<smiles>C=CN1C(=O)c2ccccc2C1=O</smiles><smiles>CCOC(=O)C=[W]</smiles><smiles>CCCCCCC</smiles><smiles>CCOC1C[C@H]1N1C(=O)c2ccccc2C1=O</smiles>

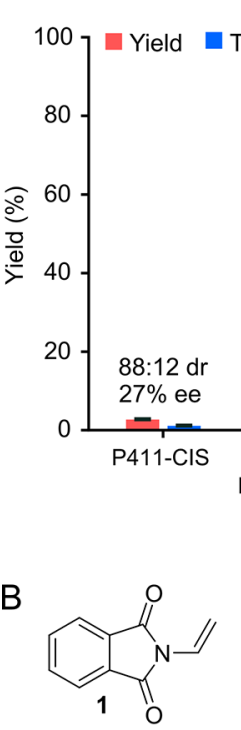

TTN

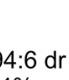
$94 \%$ ee
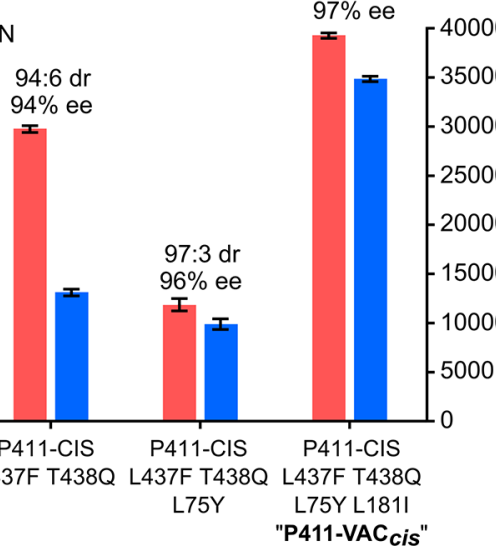

40000

5000

0000

5000

20000 Z

15000

0000 000

P411-CIS "P411-VAC cis"

B
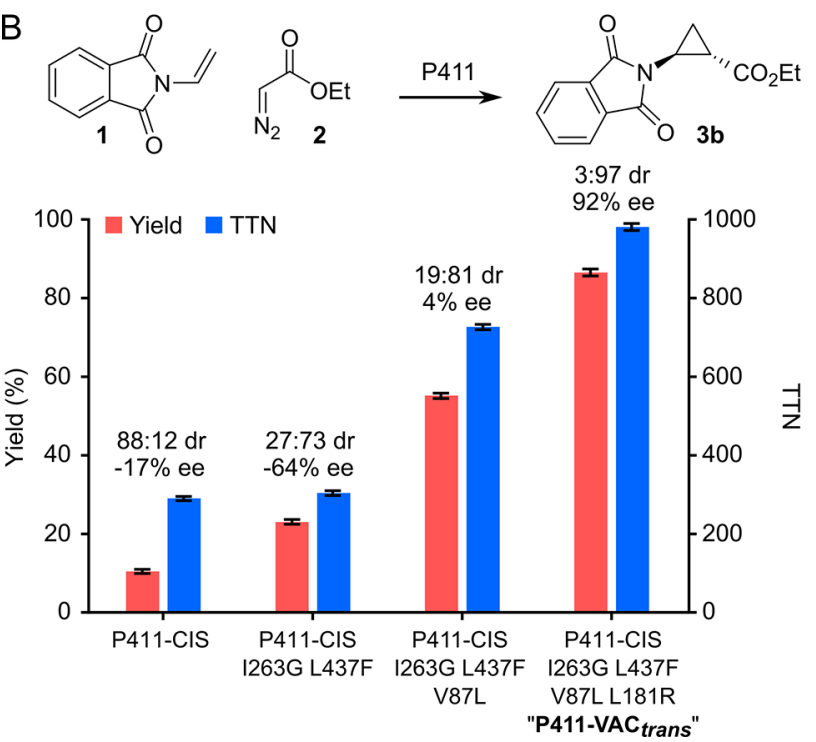

Figure 1. Directed evolution of $\mathrm{P} 411_{\mathrm{BM}_{3}} \mathrm{CIS}$ for cis- and transselective cyclopropanation of $N$-vinylphthalimide (1). Yields were determined by liquid chromatography (LC) analysis. Enantioselectivities are given for the respective diastereomers. (A) Evolutionary lineage for cis-selective $\mathrm{N}$-vinylphthalimide cyclopropanation. Reactions were performed with whole $E$. coli cells at $\mathrm{OD}_{600}=30$ expressing the indicated variants, $30 \mathrm{mM} \mathrm{N}$-vinylphthalimide (1), and $60 \mathrm{mM}$ EDA (2) under anaerobic conditions. (B) Evolutionary lineage for trans-selective $N$-vinylphthalimide cyclopropanation. Reactions were performed with whole $E$. coli cells at $\mathrm{OD}_{600}=30$ expressing the indicated variants, $5 \mathrm{mM} \mathrm{N}$-vinylphthalimide (1) and $10 \mathrm{mM}$ EDA (2).

L181, I263, T268, L437, and T438, positions previously shown to influence P450-catalyzed non-natural carbene and nitrene transfer activities (see Figure S3 in the Supporting Information $)^{30,36}$ and screened the resulting libraries for cyclopropanation on $\mathrm{N}$-vinylphthalimide with EDA. Several mutations at these positions yielded improved catalysts (see Table S3 in the Supporting Information); in addition, we found that mutation I263G, located above the heme co-factor, reversed diastereoselectivity from favoring cis-3 (88:12) to favoring trans-3 (28:72), as the mutation I263A does in P450catalyzed styrene cyclopropanation. ${ }^{30}$ To identify the optimal 
combination of activating mutations, we screened a recombination library encompassing a set of eight beneficial single active-site mutations (Table S3). From this library, we identified two variants with improved activity relative to P41 $1_{\mathrm{BM}_{3}}$-CIS as well as complementary trans and cis diastereoselectivity: variant P411 $1_{\mathrm{BM} 3}$-CIS L437F T438Q favors the cis cyclopropane product (94:6 dr, 94\% enantiomeric excess (ee)), while P411 $1_{\mathrm{BM}_{3}}$-CIS I263G L437F favors the trans (27:73 $\mathrm{dr},-64 \%$ ee) (Figure 1).

We next chose to optimize the cis- and trans-selective P411 variants separately, with the aim of evolving highly active catalysts for the selective synthesis of each cyclopropane diastereomer. For the cis-selective variant, iterative sitesaturation mutagenesis and screening delivered variant P411 $1_{\mathrm{BM} 3}$-CIS L437F T438Q L75Y L181I; we refer to this evolved cis-selective vinyl amide cyclopropanation catalyst as P411-VAC cis . This enzyme is a highly active and selective catalyst: when used in whole $E$. coli cells (with typical enzyme concentrations of 0.8 to $0.9 \mu \mathrm{M}), \mathrm{P} 411-\mathrm{VAC}_{\text {cis }}$ provides almost full conversion at up to $30 \mathrm{mM}$ substrate loading with 35000 TTN, 97:3 dr and 97\% ee (Figure 1A). Up to 40000 TTN were obtained at higher substrate or lower catalyst loadings (see Figure S4 in the Supporting Information), which places P411$\mathrm{VAC}_{c i s}$ among the most active carbene transfer hemoproteins described to date. ${ }^{31,33,44}$

For the trans-selective variant P411 $1_{\mathrm{BM}_{3}}$-CIS I263G L437F, further site-saturation mutagenesis and screening yielded variant P411 $1_{\mathrm{BM} 3}$-CIS I263G L437F V87L L181R, which we term $\mathrm{P} 411-\mathrm{VAC}_{\text {trans. }}$ In whole $E$. coli cells, this variant catalyzes cyclopropanation of $N$-vinylphthalimide with EDA in $86 \%$ yield with $980 \mathrm{TTN}, 3: 97 \mathrm{dr}$, and 92\% ee (Figure 1B).

Kinetic analyses revealed that, in the whole-cell context, P411-VAC cis displays an apparent turnover frequency (TOF) of $390 \mathrm{~min}^{-1}$ over the first $10 \mathrm{~min}$ and maintains activity over several hours (see Figure 2, as well as Figure S5 in the Supporting Information). This long catalyst lifetime is notable among hemoprotein carbene transferases, as many of those described to date suffer from rapid inactivation through transfer of the reactive carbene intermediate to protein side chains or the porphyrin co-factor. ${ }^{44,45}$ Indeed, such "burnout" behavior was observed for the evolved trans-selective variant P411$\mathrm{VAC}_{\text {trans }}$, which shows much lower TTNs than P411-VAC $\mathrm{C}_{\text {is }}$ and loses its catalytic activity after 30-60 min (Figure 2B). Thus, $\mathrm{P}_{411-\mathrm{VAC}_{\text {cis }}}$ may possess an active site structure that effectively directs iron carbenoid reactivity toward the intended alkene substrate while suppressing self-alkylation. We anticipate that future work to identify biochemical and structural determinants responsible for the long catalyst lifetime of $\mathrm{P} 411-\mathrm{VAC}_{c i s}$ (and the shorter lifetime of $\mathrm{P} 411-\mathrm{VAC}_{\text {trans }}$ ) will aid the design of highly active carbene transfer catalysts for other substrates and reaction classes.

Cyclopropanation of heteroatom-substituted alkenes also proceeds with the purified P411 enzymes, although with significantly lower efficiencies. In vitro, $\mathrm{P} 411-\mathrm{VAC}_{\text {cis }}$ catalyzes $\mathrm{N}$-vinylphthalimide cyclopropanation with a TOF of $22 \mathrm{~min}^{-1}$ and 31\% yield, 620 TTN, 91:9 dr and 93\% ee, demonstrating significant decreases in all parameters, compared to whole-cell conditions (see Figure $2 \mathrm{~A}$, as well as Table S4 in the Supporting Information). This agrees with previous findings of enhanced hemoprotein carbene transfer activity in whole cells, compared to purified protein, ${ }^{31,44,46}$ which we speculate is due to reduced EDA-induced protein alkylation and inactivation in the intact cells. Catalyst activity and lifetime is
A P411 variants, TOF $\left(\mathrm{min}^{-1}\right)$ Purified protein: Whole cells: \begin{tabular}{lcc} 
P411-CIS & 2.2 & n.d. \\
\hline P411-VAC $_{\text {trans }}$ & 4.8 & 36 \\
\hline P411-VAC $_{\text {cis }}$ & 22 & 390
\end{tabular}
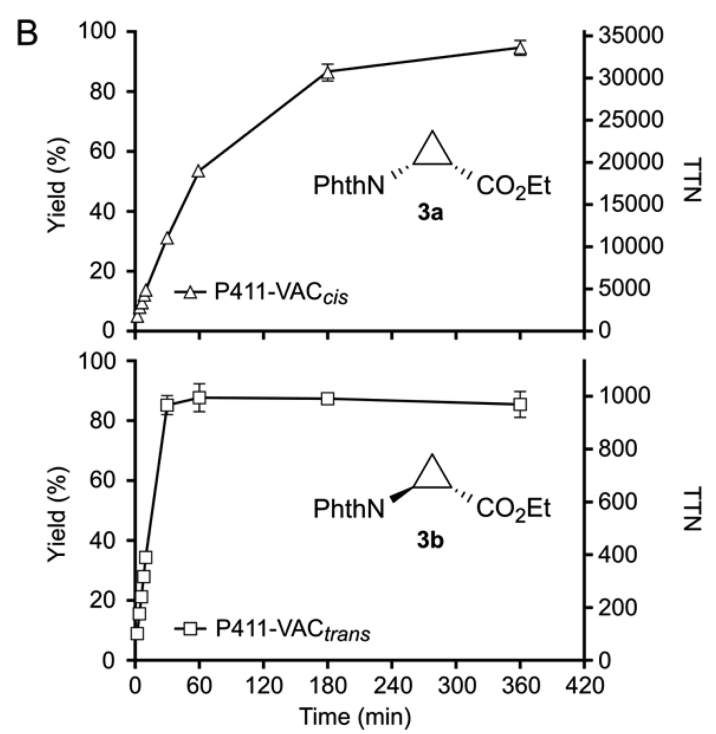

Figure 2. Kinetics of Cytochrome P411-catalyzed $N$-vinylphthalimde cyclopropanation. (A) Apparent turnover frequency observed with purified protein and whole-cell catalysts ("n.d." = not determined). (B) Reaction kinetics of whole-cell catalysts expressing P411-VAC $\mathrm{V}_{\text {cis }}$ or P411-VAC trans, recorded over $6 \mathrm{~h}$. Results are the average of duplicate reactions at each time point. Reaction conditions for P411-VAC $\mathrm{V}_{c i s}$ and P411-VAC trans $_{\text {are as shown in Figure } 1 .}$

thus strongly influenced by the reaction (cellular) environment, as well as the protein sequence.

To demonstrate the synthetic utility of the evolved cis- and trans-selective variants, we performed preparative-scale syntheses with $N$-vinylphthalimide and EDA. From a $4.0 \mathrm{mmol}$ reaction with $\mathrm{P} 411-\mathrm{VAC}_{c i s}$, cyclopropane 3a was isolated in 96\% yield (996 mg) with 97:3 dr and 97\% ee, demonstrating facile gram-scale cyclopropane synthesis enabled by this variant. Using P411-VAC trans, a $0.125 \mathrm{mmol}$ scale reaction delivered $88 \%$ yield $(28.5 \mathrm{mg})$ of the trans-cyclopropane $3 \mathrm{~b}$ with $3: 97 \mathrm{dr}$ and $92 \%$ ee (Scheme 2). The reactions did not require a slow

Scheme 2. Syntheses of Phthalimide-Protected Aminocyclopropanes with cis- and trans-Selective P411 Variants

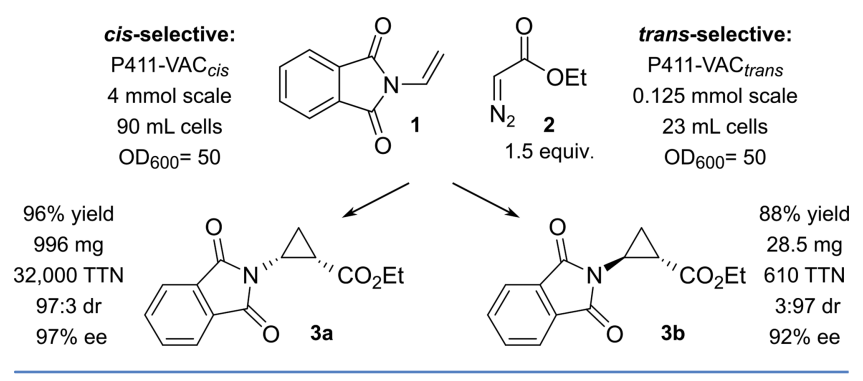

addition of substrates, and products were readily obtained in high purity after extraction from the aqueous phase and silica flash column chromatography. Absolute configurations were assigned by crystallization of the trans-cyclopropane $\mathbf{3 b}$, which revealed the compound to be the $(1 S, 2 S)$ isomer (see Figure $S 1$ in the Supporting Information). The cyclopropanation of styrene by $\mathrm{P} 411-\mathrm{VAC}_{\text {cis }}$ was used to assign the configuration of 
the cis-cyclopropane $\mathbf{3 a}$ as $(1 S, 2 R$ ) (see Figure $S 2$ in the Supporting Information).

We next tested the substrate scopes of P411-VAC $\mathrm{VAs}_{\text {is }}$ and $\mathrm{P} 411-\mathrm{VAC}_{\text {trans }}$ across a range of structurally diverse $\mathrm{N}-, \mathrm{O}-$, and S-substituted olefins. We were delighted to find that P411$\mathrm{VAC}_{\text {trans }}$ performs highly stereoselective cyclopropanation of $\mathrm{N}$ vinylcaprolactam, $\mathrm{N}$-vinylpyrrolidone, and $\mathrm{N}$-methyl- $\mathrm{N}$-vinylacetamide, delivering the corresponding cyclopropanes in $57 \%-65 \%$ isolated yield with up to $4: 96 \mathrm{dr}$ and $95 \%$ ee (see Table 1). Variant P411-VAC cis $_{\text {is }}$ also catalyzes cyclopropanation of these substrates, but with lower levels of enantiocontrol between 4\% ee and 59\% ee (see Figure S6 in the Supporting Information). The results varied across other substrates tested: for phenyl vinyl sulfide, both catalysts failed to achieve good diastereoselectivity or enantioselectivity. For phenyl vinyl ether, we observed a switch in diastereoselectivity, with P411-VAC selectively providing the trans product $(22: 78 \mathrm{dr}$, 95\% ee), while $\mathrm{P} 411-\mathrm{VAC}_{\text {trans }}$ yielded the cis product with low selectivity (61:39 dr, 26\% ee) (see Figure S6). Lastly, both variants accept the bulky $N$-vinylcarbazole as a substrate, with P411-VAC $\left(6: 94 \mathrm{dr}, 94 \%\right.$ ee) again outperforming P411-VAC $\mathrm{V}_{\text {cis }}$ (44:56 dr, $22 \%$ ee) in both diastereoselectivity and enantioselectivity.

To improve the performance of P411- $\mathrm{VAC}_{c i s}$ across these different substrates, we performed one additional round of mutagenesis and screening. A small library of 14 P411-VAC ${ }_{c i s}$ variants with single active-site mutations at residues V87, I263, E267, and A328 (see Table S5 in the Supporting Information) was screened for cyclopropanation activity on $\mathrm{N}$-vinylpyrrolidone, $\mathrm{N}$-methyl- $\mathrm{N}$-vinylacetamide, phenyl vinyl sulfide, and phenyl vinyl ether. This approach yielded P411-VAC variants showing improvements in both $\mathrm{dr}$ and ee across these substrates (Figure S6 and Table 1). For $\mathrm{N}$-vinylpyrrolidone and $\mathrm{N}$-vinylcaprolactam, introduction of the V87T mutation increased enantioselectivity from $4 \%$ ee to $74 \%$ ee and from $59 \%$ ee to $88 \%$ ee, respectively. Interestingly, the V87T mutation also turned P411-VAC ${ }_{\text {cis }}$ into a competent catalyst for cis-selective cyclopropanation of phenyl vinyl ether $(72: 28 \mathrm{dr}$, $87 \%$ ee). For $N$-methyl- $N$-vinylacetamide, ee was increased from $28 \%$ to $97 \%$ through an E267N mutation. For cis-selective cyclopropanation of phenyl vinyl sulfide, an A328N mutation improved diastereoselectivity from 59:41 dr to 84:16 dr while increasing the ee from $39 \%$ to $90 \%$, thereby delivering a cyclopropane core allowing extensive further functionalization with high selectivity. ${ }^{47}$ Moreover, this approach yielded P411$\mathrm{VAC}_{c i s}$ variants with good to excellent diastereoselectivities and enantioselectivities for the trans-selective cyclopropanation of phenyl vinyl ether and phenyl vinyl sulfide, through a V87I and V87F mutation, respectively (Table 1, Figure S6). We thereby generated a panel of P411 variants delivering diverse heteroatom-substituted cyclopropanes with good to excellent $\mathrm{dr}$ and ee (Table 1). Because high-resolution protein structures of these variants are currently lacking, it is difficult to speculate on the factors steering their enzymatic activity and cis- versus trans-selectivity. We note, however, the important role of position 87 in controlling diastereo- and enantioselectivity, as previously reported. ${ }^{39,48,49}$ Given the malleability of the P4 $11_{\mathrm{BM} 3}$ active site observed in our studies, we expect that the variants described here can be optimized further for highly selective cyclopropanation of other, related substrates.

In summary, this work demonstrates that Cytochrome P411 can synthesize heteroatom-bearing cyclopropanes, which is a valuable product class that has been widely studied for their unique physical properties as well as pharmaceutical
Table 1. Substrate Scope of cis- and trans-Selective Heteroatom-Substituted Alkene Cyclopropanation ${ }^{a}$

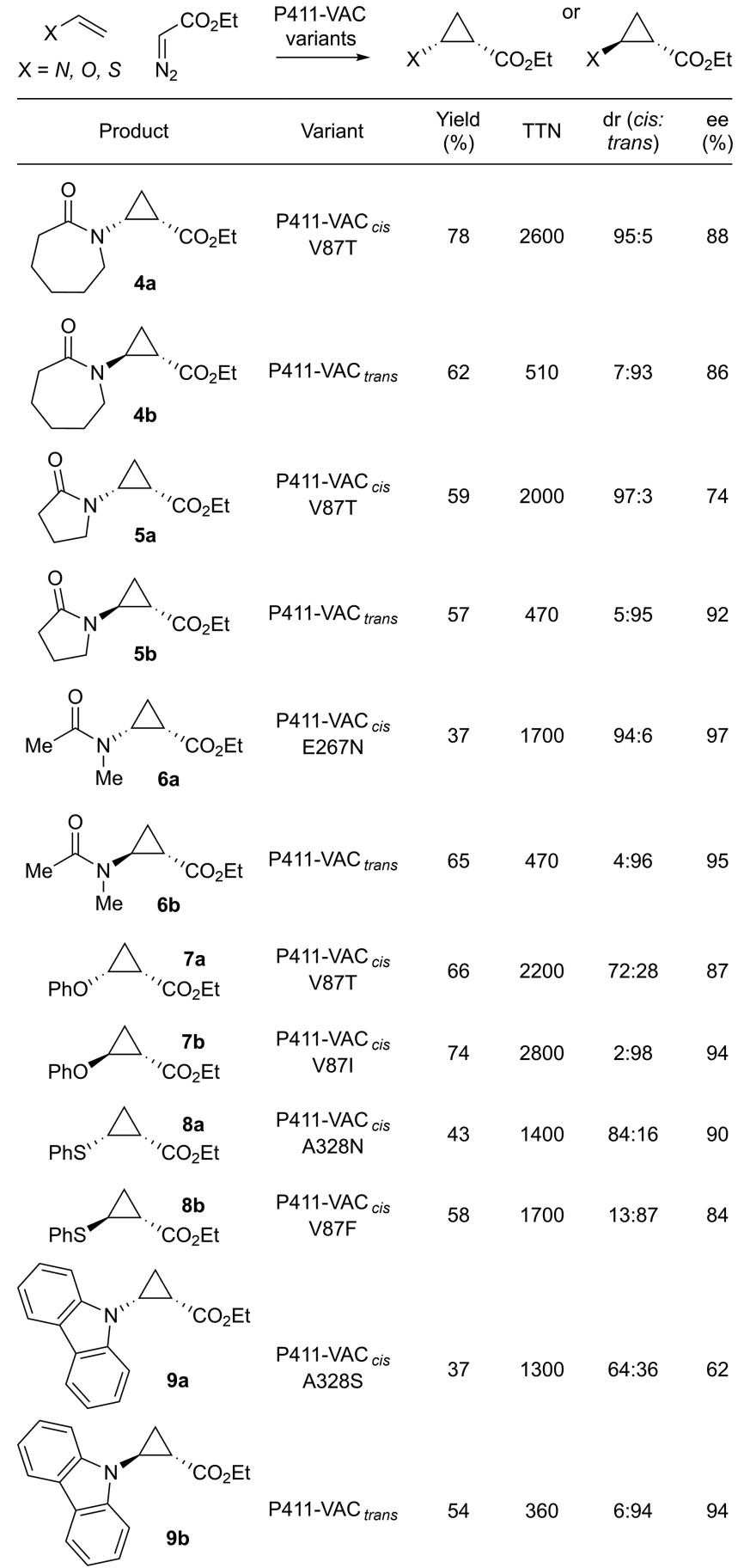

${ }^{a}$ Reactions were performed on $0.125 \mathrm{mmol}$ scale with whole $E$. coli cells at $\mathrm{OD}_{600}=50,5 \mathrm{mM}$ alkene, and $10 \mathrm{mM}$ EDA. Isolated yields are reported. Enantioselectivities are given for the major diastereomers.

applications and was previously inaccessible by enzymatic cyclopropanation. The evolved P411 variants provide N,O,Scyclopropanes with high diastereoselectivities and enantioselectivities, function under mild reaction conditions (at room temperature in an aqueous buffer), and provide higher total turnovers than reported for chemocatalysts for these transformations (no more than $400 \mathrm{TTN}$ ). ${ }^{26}$ Together with recent reports from this laboratory and others demonstrating enzymatic cyclopropanation of unactivated, aliphatic alkenes ${ }^{39}$ 
and complex natural products, ${ }^{43}$ this work demonstrates that hemoproteins are not limited to styrenyl substrates. The P411 catalysts, which consist of an iron co-factor and a protein scaffold produced in bacterial cells without need for purification, make these reactions a sustainable alternative to approaches requiring precious metals. Furthermore, the enzyme catalysts can go beyond existing chemical catalysts to generate the cis-cyclopropanes with high stereoselectivity. This expansion of enzymatic activity from model substrates (styrenes) to more diverse and functionalized starting materials such as vinylamides will broaden the scope and potential applications of non-natural biocatalysis in synthetic biology.

\section{ASSOCIATED CONTENT}

\section{S Supporting Information}

The Supporting Information is available free of charge on the ACS Publications website at DOI: 10.1021/acscatal.7b04423.

\section{Crystallographic data (CIF)}

Experimental procedures, supplementary data, calibration curves, and characterization of cyclopropanation products (PDF)

\section{AUTHOR INFORMATION}

\section{Corresponding Author}

*E-mail: frances@cheme.caltech.edu.

\section{ORCID}

Oliver F. Brandenberg: 0000-0001-5662-1234

Christopher K. Prier: 0000-0003-0902-1636

Kai Chen: 0000-0002-3325-3536

Anders M. Knight: 0000-0001-9665-8197

Frances H. Arnold: 0000-0002-4027-364X

\section{Present Address}

${ }^{\S}$ Present address: Merck Research Laboratories, Merck \& Co., P.O. Box 2000, Rahway, NJ 07065, USA.

\section{Author Contributions}

The manuscript was written with contributions of all authors. All authors have given approval to the final version of the manuscript.

\section{Funding}

This work was supported in part by the National Science Foundation, Division of Molecular and Cellular Biosciences (Grant No. MCB-1513007) and the Defense Advanced Research Projects Agency Biological Robustness in Complex Settings Contract HR0011-15-C-0093. O.F.B. acknowledges support from the Deutsche Forschungsgemeinschaft (DFG Grant No. BR 5238/1-1) and the Swiss National Science Foundation (SNF Grant No. P300PA-171225). C.K.P. thanks the Resnick Sustainability Institute for a postdoctoral fellowship. A.M.K. and Z.W. acknowledge support from the NSF Graduate Research Fellowship (Grant No. 1745301), and A.M.K. acknowledges support from Caltech's Center for Environmental Microbial Interactions.

\section{Notes}

The authors declare no competing financial interest.

\section{ACKNOWLEDGMENTS}

We thank Dr. Stephan Hammer for help with chiral separations of cyclopropylamines and all members of the Arnold Laboratory for stimulating comments and discussions. We thank Dr. David Rozzell for suggestions on cyclopropanation substrate scope.

\section{REFERENCES}

(1) Wong, H. N. C.; Hon, M.-Y.; Tse, C.-W.; Yip, Y.-C.; Tanko, J.; Hudlicky, T. Use of cyclopropanes and their derivatives in organic synthesis. Chem. Rev. 1989, 89, 165-198.

(2) Chen, D. Y.-K.; Pouwer, R. H.; Richard, J.-A. Recent advances in the total synthesis of cyclopropane-containing natural products. Chem. Soc. Rev. 2012, 41, 4631-4642.

(3) Geng, X.; Jin, L.; Shimada, M.; Kim, M. G.; Mackey, D. The phytotoxin coronatine is a multifunctional component of the virulence armament of Pseudomonas syringae. Planta 2014, 240, 1149-1165.

(4) Van de Poel, B.; Van Der Straeten, D. 1-aminocyclopropane-1carboxylic acid (ACC) in plants: More than just the precursor of ethylene! Front. Plant Sci. 2014, 5, 640.

(5) Talele, T. T. The "Cyclopropyl Fragment" is a Versatile Player that Frequently Appears in Preclinical/Clinical Drug Molecules. J. Med. Chem. 2016, 59, 8712-8756.

(6) Rosenquist, A.; Samuelsson, B.; Johansson, P.-O.; Cummings, M. D.; Lenz, O.; Raboisson, P.; Simmen, K.; Vendeville, S.; de Kock, H.; Nilsson, M.; Horvath, A.; Kalmeijer, R.; de la Rosa, G.; BeumontMauviel, M. Discovery and Development of Simeprevir (TMC435), a HCV NS3/4A Protease Inhibitor. J. Med. Chem. 2014, 57, 1673-1693.

(7) Harper, S.; McCauley, J. A.; Rudd, M. T.; Ferrara, M.; DiFilippo, M.; Crescenzi, B.; Koch, U.; Petrocchi, A.; Holloway, M. K.; Butcher, J. W.; Romano, J. J.; Bush, K. J.; Gilbert, K. F.; McIntyre, C. J.; Nguyen, K. T.; Nizi, E.; Carroll, S. S.; Ludmerer, S. W.; Burlein, C.; DiMuzio, J. M.; Graham, D. J.; McHale, C. M.; Stahlhut, M. W.; Olsen, D. B.; Monteagudo, E.; Cianetti, S.; Giuliano, C.; Pucci, V.; Trainor, N.; Fandozzi, C. M.; Rowley, M.; Coleman, P. J.; Vacca, J. P.; Summa, V.; Liverton, N. J. Discovery of MK-5172, a Macrocyclic Hepatitis C Virus NS3/4a Protease Inhibitor. ACS Med. Chem. Lett. 2012, 3, 332-336.

(8) Gnad, F.; Reiser, O. Synthesis and Applications of $\beta$ Aminocarboxylic Acids Containing a Cyclopropane Ring. Chem. Rev. 2003, 103, 1603-1623.

(9) Koglin, N.; Zorn, C.; Beumer, R.; Cabrele, C.; Bubert, C.; Sewald, N.; Reiser, O.; Beck-Sickinger, A. G. Analogues of Neuropeptide Y Containing $\beta$-Aminocyclopropane Carboxylic Acids are the Shortest Linear Peptides That Are Selective for the Y1 Receptor. Angew. Chem., Int. Ed. 2003, 42, 202-205.

(10) Schneider, T. F.; Kaschel, J.; Werz, D. B. A new golden age for donor-acceptor cyclopropanes. Angew. Chem., Int. Ed. 2014, 53, 55045523.

(11) Reissig, H.-U.; Zimmer, R. Donor-Acceptor-Substituted Cyclopropane Derivatives and Their Application in Organic Synthesis. Chem. Rev. 2003, 103, 1151-1196.

(12) Shaw, M. H.; Bower, J. F. Synthesis and applications of rhodacyclopentanones derived from $\mathrm{C}-\mathrm{C}$ bond activation. Chem. Commun. 2016, 52, 10817-10829.

(13) Fumagalli, G.; Stanton, S.; Bower, J. F. Recent Methodologies That Exploit C-C Single-Bond Cleavage of Strained Ring Systems by Transition Metal Complexes. Chem. Rev. 2017, 117, 9404-9432.

(14) Charette, A. B.; Côté, B. Stereoselective Synthesis of All Four Isomers of Coronamic Acid: A General Approach to 3-Methanoamino Acids. J. Am. Chem. Soc. 1995, 117, 12721-12732.

(15) Miyamura, S.; Itami, K.; Yamaguchi, J. Syntheses of Biologically Active 2-Arylcyclopropylamines. Synthesis 2017, 49, 1131-1149.

(16) Belyk, K. M.; Xiang, B.; Bulger, P. G.; Leonard, W. R., Jr.; Balsells, J.; Yin, J.; Chen, C. Enantioselective Synthesis of (1R,2S)-1Amino-2-vinylcyclopropanecarboxylic Acid Ethyl Ester (Vinyl-ACCA$\mathrm{OEt}$ ) by Asymmetric Phase-Transfer Catalyzed Cyclopropanation of (E)-N-Phenylmethyleneglycine Ethyl Ester. Org. Process Res. Dev. 2010, 14, 692-700.

(17) Lou, S.; Cuniere, N.; Su, B.-N.; Hobson, L. A. Concise asymmetric synthesis of a $(1 R, 2 S)$-1-amino-2-vinylcyclopropanecarboxylic acid-derived sulfonamide and ethyl ester. Org. Biomol. Chem. 2013, 11, 6796-6805.

(18) Beaulieu, P. L.; Gillard, J.; Bailey, M. D.; Boucher, C.; Duceppe, J.-S.; Simoneau, B.; Wang, X.-J.; Zhang, L.; Grozinger, K.; Houpis, I.; Farina, V.; Heimroth, H.; Krueger, T.; Schnaubelt, J. Synthesis of (1R,2S)-1-Amino-2-vinylcyclopropanecarboxylic Acid Vinyl-ACCA) 
Derivatives: Key Intermediates for the Preparation of Inhibitors of the Hepatitis C Virus NS3 Protease. J. Org. Chem. 2005, 70, 5869-5879. (19) Bassan, E. M.; Baxter, C. A.; Beutner, G. L.; Emerson, K. M.; Fleitz, F. J.; Johnson, S.; Keen, S.; Kim, M. M.; Kuethe, J. T.; Leonard, W. R.; Mullens, P. R.; Muzzio, D. J.; Roberge, C.; Yasuda, N. Multikilogram-Scale Synthesis of a Chiral Cyclopropanol and an Investigation of the Safe Use of Lithium Acetylide-Ethylene Diamine Complex. Org. Process Res. Dev. 2012, 16, 87-95.

(20) Abu-Elfotoh, A.-M.; Phomkeona, K.; Shibatomi, K.; Iwasa, S. Asymmetric Inter- and Intramolecular Cyclopropanation Reactions Catalyzed by a Reusable Macroporous-Polymer-Supported Chiral Ruthenium(II)/Phenyloxazoline Complex. Angew. Chem., Int. Ed. 2010, 49, 8439-8443.

(21) Chanthamath, S.; Phomkeona, K.; Shibatomi, K.; Iwasa, S. Highly stereoselective $\mathrm{Ru}(\mathrm{II})-\mathrm{Pheox}$ catalyzed asymmetric cyclopropanation of terminal olefins with succinimidyl diazoacetate. Chem. Commun. 2012, 48, 7750-7752.

(22) Chanthamath, S.; Nguyen, D. T.; Shibatomi, K.; Iwasa, S. Highly Enantioselective Synthesis of Cyclopropylamine Derivatives via $\mathrm{Ru}$ (II)-Pheox-Catalyzed Direct Asymmetric Cyclopropanation of Vinylcarbamates. Org. Lett. 2013, 15, 772-775.

(23) Chanthamath, S.; Mandour, H. S. A.; Tong, T. M. T.; Shibatomi, K.; Iwasa, S. Highly stereoselective cyclopropanation of diazo Weinreb amides catalyzed by chiral $\mathrm{Ru}(\mathrm{II})-\mathrm{Amm}-\mathrm{Pheox}$ complexes. Chem. Commun. 2016, 52, 7814-7817.

(24) Xie, M.-S.; Zhou, P.; Niu, H.-Y.; Qu, G.-R.; Guo, H.-M. Enantioselective Intermolecular Cyclopropanations for the Synthesis of Chiral Pyrimidine Carbocyclic Nucleosides. Org. Lett. 2016, 18, 4344-4347.

(25) Denton, J. R.; Davies, H. M. L. Enantioselective Reactions of Donor/Acceptor Carbenoids Derived from $\alpha$-Aryl- $\alpha$-Diazoketones. Org. Lett. 2009, 11, 787-790.

(26) Sambasivan, R.; Ball, Z. T. Screening Rhodium Metallopeptide Libraries "On Bead": Asymmetric Cyclopropanation and a Solution to the Enantiomer Problem. Angew. Chem., Int. Ed. 2012, 51, 8568-8572.

(27) Garcia, P.; Diez, D.; Antón, A. B.; Garrido, N. M.; Marcos, I. S.; Basabe, P.; Urones, J. G. Stereoselective Synthesis of Cyclopropanols. Mini-Rev. Org. Chem. 2006, 3, 291-314.

(28) Moreau, B.; Charette, A. B. Expedient Synthesis of Cyclopropane $\alpha$-Amino Acids by the Catalytic Asymmetric Cyclopropanation of Alkenes Using Iodonium Ylides Derived from Methyl Nitroacetate. J. Am. Chem. Soc. 2005, 127, 18014-18015.

(29) Lindsay, V. N. G.; Lin, W.; Charette, A. B. Experimental Evidence for the All-Up Reactive Conformation of Chiral Rhodium(II) Carboxylate Catalysts: Enantioselective Synthesis of cis-Cyclopropane $\alpha$-Amino Acids. J. Am. Chem. Soc. 2009, 131, 16383-16385.

(30) Coelho, P. S.; Brustad, E. M.; Kannan, A.; Arnold, F. H. Olefin Cyclopropanation via Carbene Transfer Catalyzed by Engineered Cytochrome P450 Enzymes. Science 2013, 339, 307-310.

(31) Coelho, P. S.; Wang, Z. J.; Ener, M. E.; Baril, S. A.; Kannan, A.; Arnold, F. H.; Brustad, E. M. A serine-substituted P450 catalyzes highly efficient carbene transfer to olefins in vivo. Nat. Chem. Biol. 2013, 9, 485-487.

(32) Heel, T.; McIntosh, J. A.; Dodani, S. C.; Meyerowitz, J. T.; Arnold, F. H. Non-natural Olefin Cyclopropanation Catalyzed by Diverse Cytochrome P450s and Other Hemoproteins. ChemBioChem 2014, 15, 2556-2562.

(33) Bordeaux, M.; Tyagi, V.; Fasan, R. Highly Diastereoselective and Enantioselective Olefin Cyclopropanation Using Engineered Myoglobin-Based Catalysts. Angew. Chem., Int. Ed. 2015, 54, 1744-1748.

(34) Tinoco, A.; Steck, V.; Tyagi, V.; Fasan, R. Highly Diastereo- and Enantioselective Synthesis of Trifluoromethyl-Substituted Cyclopropanes via Myoglobin-Catalyzed Transfer of Trifluoromethylcarbene. J. Am. Chem. Soc. 2017, 139, 5293-5296.

(35) Brandenberg, O. F.; Fasan, R.; Arnold, F. H. Exploiting and engineering hemoproteins for abiological carbene and nitrene transfer reactions. Curr. Opin. Biotechnol. 2017, 47, 102-111.

(36) Wang, Z. J.; Renata, H.; Peck, N. E.; Farwell, C. C.; Coelho, P. S.; Arnold, F. H. Improved Cyclopropanation Activity of Histidine-
Ligated Cytochrome P450 Enables the Enantioselective Formal Synthesis of Levomilnacipran. Angew. Chem., Int. Ed. 2014, 53, 6810-6813.

(37) Bajaj, P.; Sreenilayam, G.; Tyagi, V.; Fasan, R. Gram-Scale Synthesis of Chiral Cyclopropane-Containing Drugs and Drug Precursors with Engineered Myoglobin Catalysts Featuring Complementary Stereoselectivity. Angew. Chem., Int. Ed. 2016, 55, 1611016114.

(38) Hernandez, K. E.; Renata, H.; Lewis, R. D.; Kan, S. B. J.; Zhang, C.; Forte, J.; Rozzell, D.; McIntosh, J. A.; Arnold, F. H. Highly Stereoselective Biocatalytic Synthesis of Key Cyclopropane Intermediate to Ticagrelor. ACS Catal. 2016, 6, 7810-7813.

(39) Knight, A. M.; Kan, S. B. J.; Lewis, R. D.; Brandenberg, O. F.; Chen, K.; Arnold, F. H.: Diverse engineered heme proteins enable stereodivergent cyclopropanation of unactivated alkenes. ACS Cent. Sci., in press. DOI: 10.1021 /acscentsci.7b00548.

(40) Key, H. M.; Dydio, P.; Clark, D. S.; Hartwig, J. F. Abiological catalysis by artificial haem proteins containing noble metals in place of iron. Nature 2016, 534, 534-537.

(41) Key, H. M.; Dydio, P.; Liu, Z.; Rha, J. Y.-E.; Nazarenko, A.; Seyedkazemi, V.; Clark, D. S.; Hartwig, J. F. Beyond Iron: IridiumContaining P450 Enzymes for Selective Cyclopropanations of Structurally Diverse Alkenes. ACS Cent. Sci. 2017, 3, 302-308.

(42) Reynolds, E. W.; Schwochert, T. D.; McHenry, M. W.; Watters, J. W.; Brustad, E. M. Orthogonal Expression of an Artificial Metalloenzyme for Abiotic Catalysis. ChemBioChem 2017, 18 2380-2384.

(43) Gober, J. G.; Ghodge, S. V.; Bogart, J. W.; Wever, W. J.; Watkins, R. R.; Brustad, E. M.; Bowers, A. A. P450-Mediated Nonnatural Cyclopropanation of Dehydroalanine-Containing Thiopeptides. ACS Chem. Biol. 2017, 12, 1726-1731.

(44) Renata, H.; Lewis, R. D.; Sweredoski, M. J.; Moradian, A.; Hess, S.; Wang, Z. J.; Arnold, F. H. Identification of Mechanism-Based Inactivation in P450-Catalyzed Cyclopropanation Facilitates Engineering of Improved Enzymes. J. Am. Chem. Soc. 2016, 138, 12527-12533.

(45) Wolf, M. W.; Vargas, D. A.; Lehnert, N. Engineering of RuMb: Toward a Green Catalyst for Carbene Insertion Reactions. Inorg. Chem. 2017, 56, 5623-5635.

(46) Kan, S. B. J.; Huang, X.; Gumulya, Y.; Chen, K.; Arnold, F. H. Genetically programmed chiral organoborane synthesis. Nature 2017, 552, 132-136.

(47) Chawner, S. J.; Cases-Thomas, M. J.; Bull, J. A. Divergent Synthesis of Cyclopropane-Containing Lead-Like Compounds, Fragments and Building Blocks through a Cobalt Catalyzed Cyclopropanation of Phenyl Vinyl Sulfide. Eur. J. Org. Chem. 2017, 2017, 5015-5024.

(48) Oliver, C. F.; Modi, S.; Sutcliffe, M. J.; Primrose, W. U.; Lian, L. Y.; Roberts, G. C. A Single Mutation in Cytochrome P450 BM3 Changes Substrate Orientation in a Catalytic Intermediate and the Regiospecificity of Hydroxylation. Biochemistry 1997, 36, 1567-1572.

(49) Vottero, E.; Rea, V.; Lastdrager, J.; Honing, M.; Vermeulen, N. P.; Commandeur, J. N. Role of residue 87 in substrate selectivity and regioselectivity of drug-metabolizing cytochrome P450 CYP102A1M11. J. Biol. Inorg. Chem. 2011, 16, 899-912. 